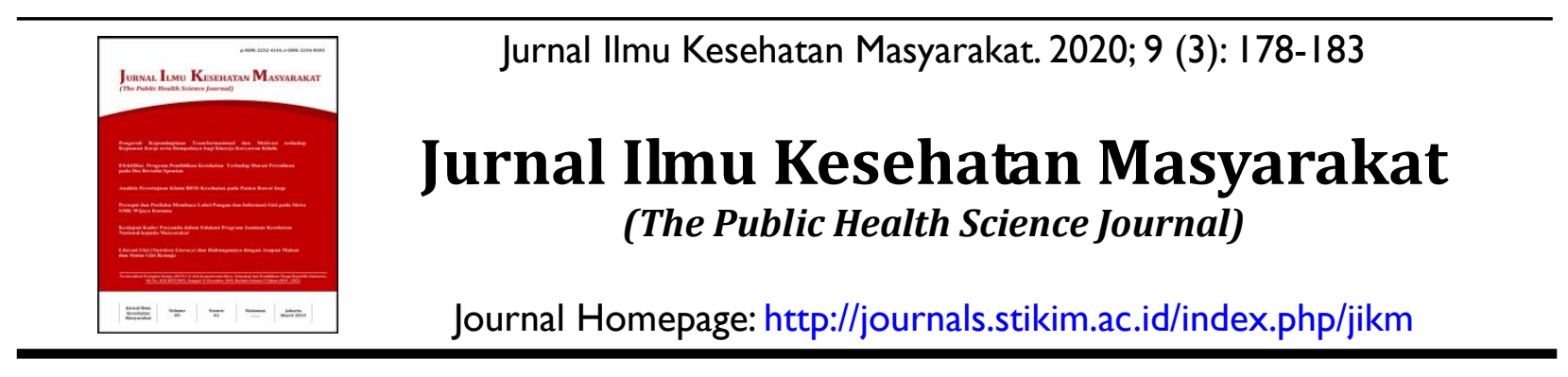

\title{
Hubungan Senam Prenatal Yoga dengan Tingkat Kecemasan Ibu Hamil Primigravida Trimester III
}

\author{
Ronalen Br. Situmorang ${ }^{1}$, Taufianie Rossita ${ }^{2}$, Diyah Tepi Rahmawati ${ }^{3}$ \\ 1,2,3Program Studi Kebidanan, Universitas Dehasen Bengkulu, \\ Jl. Meranti Raya No.32 Sawah Lebar Bengkulu, 38228 \\ Email : ronalen.situmorang@unived.ac.id', taufianirossita@unived.ac.id², diyahtepi@unived.ac.id³
}

\begin{abstract}
Abstrak
Yoga dapat memberikan pengaruh positif pada kesehatan tubuh, psikologi, perasaan. Tujuan latihan yoga menciptakan keseimbangan jiwa, raga, ketenangan, mempersiapkan ibu hamil secara fisik, mental, spiritual proses persalinan. Dengan ada persiapan, ibu akan lebih percaya diri dan memperoleh keyakinan menjalani persalinan dengan lancar serta tidak mengalami kecemasan. Tujuan penelitian ini untuk mengetahui hubungan senam prenatal yoga dengan tingkat kecemasan pada ibu hamil primigravida trimester III. Metode penelitian kuantitatif bivariat dengan pendekatan Quasy Eksperimenpre pre post test with one group design. Analisis data menggunakan uji Statistik T-Test Dependen. Sampel sebanyak 33 ibu hamil primigravida trimester III dengan tehnik purposive sampling. Hasil penelitian menunjukkan bahwa senam prenatal yoga menurunkan tingkat kecemasan pada ibu hamil primigravida yang berarti terdapat perbedaan yang bermakna antara senam prenatal yoga dengan tingkat kecemasan pada ibu hamil primigravida trimester III $(\mathrm{Pv}=0,000)$. Senam yoga merupakan senam yang sangat aman, mudah, praktis dan perlu diterapkan secara mandiri dan berkesinambungan untuk dapat meningkatkan kesehatan. Namun masih diperlukan penelitian lanjutan untuk hasil yang lebih valid dan relevan.
\end{abstract}

Kata Kunci : Ibu hamil primigravida, kecemasan, senam prenatal yoga

\begin{abstract}
Yoga can have a positive influence on body health, psychology, feelings. The purpose of yoga practice is to create a balance of mind, body, calmness, and prepare pregnant women physically, mentally, spiritually for childbirth. With preparation, the mother will be more confident and gain the confidence to go through labor smoothly and not experience anxiety. The purpose of this study was to determine the relationship between prenatal yoga and anxiety levels in third trimester primigravida pregnant women. Bivariate quantitative research method with a Quasy Experiment approach pre post test with one group design. The data analysis used the Dependent T-Test Statistics. A sample of 33 primigravida pregnant women trimester III with purposive sampling technique. The results showed that prenatal yoga exercise reduced anxiety levels in primigravida pregnant women, which means that there was a significant difference between prenatal yoga exercise and anxiety levels in third trimester primigravida pregnant women $(P v=0,000)$. Yoga exercise is an exercise that is very safe, easy, practical and needs to be applied independently and continuously in order to improve health. However, further research is still needed for more valid and relevant results.
\end{abstract}

Keywords: Primigravida pregnant women, anxiety, prenatal yoga exercise 


\section{Pendahuluan}

Pada kehamilan trimester ke tiga terutama pada primigravida, tingkat kecemasan pada ibu hamil dapat semakin berat dan sering, hal ini dapat menyebabkan terjadinya kelahiran bayi dengan premature akibat dari kecemasan ibu hamil. ${ }^{1}$ Kecemasan yang terdapat pada saat sedang hamil dapat meningkatkan hormon stres sehingga dapat menyebabkan gangguan aliran darah di dalam rahim serta dapat mengakibatkan lemahnya kontraksi otot-otot rahim. Hal ini dapat menyebabkan bahwa makin lamanya proses persalinan (partus lama), risiko sectio caesaria, dan persalinan dengan menggunakan alat. Sedangkan resiko yang terjadi pada bayi adalah dapat menyebabkan kelainan bawaan berupa kegagalan akan penutupan celah palatum, kelahiran prematur, bayi Berat Badan Lahir Rendah (BBLR), kegawatan (fetal distres) serta dalam jangka panjang dapat berkaitan dengan gangguan perilaku dan emosi anak. ${ }^{2,3}$

Yoga adalah suatu metode penyembuhan yang memberikan pengaruh positif pada kesehatan tubuh, psikologi, perasaan, dan reaksi terhadap kehidupan yang sedang kita jalani. Tujuan dari rangkaian latihan yoga untuk menciptakan keseimbangan jiwa dan raga, kekuatan tubuh, ketenangan, kedamaian, mempersiapkan ibu hamil secara fisik, mental dan spiritual untuk proses persalinan. Dengan persiapan matang, ibu akan lebih percaya diri dan memperoleh keyakinan menjalani persalinan dengan lancar dan nyaman serta tidak mengalami kecemasan. $^{3-5}$

Latihan yoga tidak mempunyai efek negatif terhadap ibu dan pada perkembangan janinnya. ${ }^{6}$ Menurut Rafika, dalam hasil penelitiannya bahwa prenatal yoga sangat efektif terhadap pengurangan keluhan fisik pada ibu hamil trimester III. $^{7}$ Menurut Aswitami tentang yoga antenatal yang diberikan pada ibu hamil memiliki pengaruh yang cukup signifikan untuk mengurangi kecemasan dalam menghadapi proses persalinan. ${ }^{8}$
Didapatkan data dari Dinas Kesehatan Kabupaten Mukomuko pada tahun 2018 ditemukan jumlah ibu hamil 4.523 orang, ibu hamil trimester 3 berjumlah 3.679 orang, dan ibu hamil dengan resiko tinggi 905 orang. ${ }^{9} \quad$ Sedangkan pada tahun 2019 ditemukan jumlah ibu hamil 4.562 orang, ibu hamil trimester 3 berjumlah 1.955 orang, dan ibu hamil dengan resiko tinggi sebanyak 914 orang. ${ }^{10}$ Data di Puskesmas Perawatan Lubuk Pinang tahun 2018 didapatkan jumlah ibu hamil 367 orang, ibu hamil trimester 3 berjumlah $235(64 \%)$ dan ibu hamil dengan resiko tinggi berjumlah 73 orang. ${ }^{11}$ data pada tahun 2019 jumlah ibu hamil 378 orang, ibu hamil trimester 3 berjumlah 123 (33\%) dan ibu hamil dengan resiko tinggi berjumlah 76 orang. ${ }^{12}$

Hasil wawancara terhadap 10 orang ibu hamil yang mengalami kecemasan didapatkan 7 orang $(70 \%)$ mengalami kecemasan selama kehamilan trimester III yang berlebihan dan cemas belum pernah sama sekali mengikuti senam prenatal yoga sehingga dapat membuat ibu hamil setres hampir depresi menjalankan kehamilannya dikarenakan terlalu banyak dipikirkan dalam hidup ini dan peran ibu sudah mulai muncul untuk pertama kalinya dalam mengasuh anaknya nanti. Kecemasan masih selalu ada selama kehamilan dan ini dapat membuat kesehatan ibu dan janin dapat terganggu jika tidak dicegah lebih dini sebelum menuju kepersalinan. Sementara 3 orang $(30 \%)$ ibu hamil tidak mengalami kecemasan selama hamil.

Terdapat beberapa cara tindakan dalam pencegahan selama kehamilan agar ibu dan janin selalu berada dalam kondisi sehat dan nantinya terjadi proses persalinan normal yaitu dapat dilakukan dengan cara olah raga seperti jalan pagi, bersepeda statis, aerobic, senam air, menari, dan yoga. Senam hamil memiliki beberapa metode latihan diantaranya yaitu yoga, pilates, kegel, hypnotherapy. ${ }^{7}$ Mengikuti senam prenatal yoga secara teratur dan intensif dapat menjaga kesehatan tubuh dan psikologis ibu hamil serta janin. ${ }^{13}$ Senam prenatal yoga dapat dilakukan setiap hari selama 60 menit 
dan dapat dilakukan sepanjang kehamilan. Selama tidak ada peregangan otot perut, yoga sangat bermanfaat untuk membantu ibu hamil lebih rileks dan santai. ${ }^{4}$ Latihan yoga tidak mempunyai efek negatif terhadap ibu dan pada perkembangan janinnya. ${ }^{6}$

Yoga merupakan suatu bentuk seni ilmu pengetahuan kuno yang berasal dari India yang semula di rancang untuk memperkuat dan membentuk sikap tubuh serta menenangkan dan memusatkan pikiran untuk masuk kedalam kondisi meditasi. Yoga telah berhasil diadaptasi untuk berbagai kepentingan dan gaya hidup dari orang-orang barat, sehingga yoga dikenal sebagai salah satu seni olahraga. Tujuan yoga adalah kesehatan tubuh, janin dan ketentraman serta ketenangan pikiran. Penelitian terkait hubungan senam prenatal yoga dengan tingkat kecemasan ibu hamil primigravida trimester III di Indonesia masih relatif sedikit. Dari latar belakang tersebut, maka penelitian ini bertujuan mengetahuihubungan senam prenatal yoga dengan tingkat kecemasan ibu hamil primigravida trimester III.

\section{Metode}

Penelitian ini menggunakan desain quasy eksperiment dengan pendekatan pretest- postest one group desain. Populasi dalam penelitian ini yaitu seluruh ibu hamil primigravida trimester III yang memiliki kecemasan selama kehamilan di Kabupaten Mukomuko sebanyak 33 responden. Sampel dalam penelitian ini adalah ibu hamil yang mengalami kecemasan selama kehamilan di Kabupaten Mukomuko dan diperoleh dengan tehnik total sampling.

Sumber data pada penelitian ini menggunakan data primer yaitu data yang diambil secara langsung dari ibu hamil trimester III dalam melaksanakan senam prenatal yoga, lembar skala tingkat kecemasan HARS (Hamilton Anxiety Rating Scale). Pengumpulan data primer dilakukan langsung oleh peneliti. Data sekunder dalam penelitian ini adalah identitas responden. Dalam penelitian ini dilakukan pengukuran sebanyak dua kali yaitu sebelum dan sesudah intervensi (pemberian senam prenatal yoga) dilakukan oleh enumerator yaitu oleh anggota peneliti.

Instrumen yang digunakan untuk mengukur skala tingkat kecemasan yaitu skala HARS (Hamilton Anxiety Rating Scale) yang terdiri dari 14 item, dengan skala masing-masing item $0-4$, dengan total skor keseluruhan 0-56. Kategori tingkat kecemasan berdasarkan skala HARS adalah $0=$ tidak ada gejala sama sekali; $1=$ gejala ringan, apabila terdapat 1 dari semua gejala yang ada; $2=$ gejala sedang jika terdapat separuh dari gejala yang ada; $3=$ gejala berat jika terdapat lebih dari separuh dari gejala yang ada; 4= gejala berat sekali jika terdapat semua gejala yang ada. Masing-masing nilai dari 14 kelompok gejala dijumlahkan dan dinilai derajat kecemasannya, yaitu: 0 . $\leq 6=$ Tidak ada kecemasan, 1. 7-14= Kecemasan ringan, 2. 15-27=Kecemasan sedang dan 3. $>27=$ kecemasan berat. $^{8}$

Kelompok pada penelitian ini adalah ibu hamil yang mengalami tingkat kecemasan diberikan perlakuan sebelum dan sesudah dilakukan senam prenatal yoga dan dilakukan sebanyak 6 kali selama 3 minggu dan setiap melakukan senam yoga dengan durasi 60 menit. Waktu dilakukan pre test yaitu awal pertemuan hari pertama sebelum yoga diberikan dan post test dilakukan pada akhir pertemuan setelah 6 kali diberikan yoga. Instrumen yang digunakan untuk mengukur kecemasan adalah menggunakan lembar skala tingkat kecemasan HARS (Hamilton Anxiety Rating Scale). Variabel penelitian terdiri dari variabel indenpenden (senam prenatal yoga) dan variabel dependen (tingkat kecemasan ibu hamil). Analisis data yang digunakan adalah analisis univariat yaitu analisis untuk mendeskripsikan distribusi frekuensi subjek penelitian, dan analisis bivariat yaitu untuk membuktikan bahwa masing-masing variabel dapat berhubungan, uji yang dilakukan adalah uji T-Test Dependen melihat perbedaan pada satu kelompok sebelum dan sesudah perlakuan. ${ }^{14}$ 


\section{Hasil}

Tabel 1. Hubungan tingkat kecemasan sebelum dan sesudah senam prenatal yoga pada ibu hamil primigravida trimester III di Kabupaten Mukomuko Provinsi Bengkulu

\begin{tabular}{lccccc}
\hline \multirow{2}{*}{ Tingkat Kecemasan } & \multicolumn{2}{c}{$\begin{array}{c}\text { Sebelum Senam Prenatal } \\
\text { Yoga }\end{array}$} & \multicolumn{2}{c}{$\begin{array}{c}\text { Sesudah Senam Prenatal } \\
\text { Yoga }\end{array}$} & \multirow{2}{*}{ Pvalue } \\
\cline { 2 - 5 } & $\mathbf{n}$ & $\mathbf{n}$ & $\mathbf{n}$ & $\mathbf{\%}$ & 0,000 \\
\hline Tidak Ada Kecemasan & 0 & 0 & 24 & 72,7 & \\
Kecemasan Ringan & 4 & 12,1 & 9 & 27,3 & \\
Kecemasan Sedang & 18 & 54,6 & 0 & 0 & \\
Kecemasan Berat & 11 & 33,3 & 0 & 0 & \\
\hline
\end{tabular}

Tabel diatas menunjukkan bahwa dari 33 responden sebelum diberikan senam prenatal yoga sebagian besar mengalami kecemasan sedang $(54,6 \%)$ hingga berat $(33,3 \%)$. Sedangkan setelah diberikan intervensi berupa senam prenatal yoga, sebagian besar ibu hamil primigravida tidak mengalami kecemasan $(72,2 \%)$. Hasil uji statistik menunjukkan nilai Pvalue $=0,000<$ $\alpha(0,05)$ dengan uji T-Test Dependen yang berarti terdapat perbedaan yang bermakna tingkat kecemasan sebelum dan sesudah dilakukannya intervensi (dilakukan senam prenatal yoga pada ibu hamil primigravida trimester III).

\section{Pembahasan}

Yoga adalah salah kegiatan olah tubuh, pikiran dan mental yang sangat membantu ibu hamil dalam melenturkan persendian dan menenangkan pikiran terutama pada ibu hamil trimester III. ${ }^{8,15}$ Dari hasil penelitian ini diketahui bahwa senam prenatal yoga dapat menurunkan tingkat kecemasan pada ibu hami primigravida. Ibu hamil yang diberikan senam prenatal yoga dapat membuat ibu menjadi relaks, tenang dan tidak cemas lagi selama kehamilannya. Senam yoga dapat dilakukan sebanyak 2 kali seminggu selama 3 minggu dengan waktu 60 menit sekali yoga.

Dengan adanya yoga prenatal dapat mengurangi ketegangan otot tubuh yang dapat ditandai dengan pelemasan pada otot pada sekitar punggung, perut, kaki dan disertai pengaturan nafas yang teratur sehinggga dapat membuat tubuh menjadi lebih nyaman, tenang dan menjadi relaks. ${ }^{15,16}$ Dengan adanya yoga prenatal dapat mengurangi ketegangan otot tubuh yang dapat ditandai dengan pelemasan pada otot pada sekitar punggung, perut, kaki dan disertai pengaturan nafas yang teratur sehinggga dapat membuat menjadi relaks. ${ }^{5,15,17}$

Hasil penelitian ini tidak jauh berbeda dengan penelitian Parmiana Bangun, yang menyatakan bahwa Senam yoga sangat ideal untuk kehamilan dan saat setelah mengahadapi persalinan karena menjadi sarana bagi wanita untuk melatih fisik dan spritual serta mengembangkan kepercayaan diri dan kesadaran diri, salah satunya terhadap stress. Hasil penelitiannya menunjukkan bahwa terdapat hubungan yang kuat antara tingkat kecemasan dalam menghadapi persalinan antara yang melakukan dan tidak melakukan senam yoga pada primigravida. ${ }^{16,18}$ Manfaat Yoga prenatal dapat meningkatkan kekuatan konsentrasi, dapat meningkatkan daya ingat, meningkatkan durasi tidur, mengatasi gangguan mata, menghilangkan insomnia, meringankan pikiran dan permasalahan dan emosi yang terpendam dan tentunya ibu hamil lebih siap dalam menghadapi persalinan dengan lancer. $8,15,19$

Dalam penelitian yang dilakukan oleh Ni Gusti Ayu Pramita Aswitami, terdapat pengaruh yoga antenatal terhadap tingkat kecemasan pada ibu hamil TW III dalam menghadapi proses persalinan, dimana senam yoga merupakan salah kegiatan olah tubuh, pikiran dan mental yang sangat membantu ibu hamil dalam melenturkan persendian dan menenangkan pikiran terutama pada ibu hamil trimester III. Yoga antenatal yang diberikan pada ibu hamil 
memiliki pengaruh yang cukup signifikan untuk mengurangi kecemasan dalam menghadapi proses persalinan. ${ }^{4,8}$

Adapun kecemasan pada saat kehamilan dapat sering timbul dikarenakan ibu merasa tidak mampu untuk dapat menjalankan tugasnya sebagai ibu bagi anak-anaknya, kecemasan yang muncul pada saat kehamilan adalah kecemasan yang timbul karena individu dihadapinya pada situasi-situasi tertentu yang penuh tuntutan dalam menjelang bersalin atau melahirkan. ${ }^{18}$ Penelitian-penelitian terkait kecemasan dengan senam prenatal yoga telah dilakukan menegaskan bahwa senam yoga merupakan senam yang nyaman dilakukan pada ibu hamil, dimana senam yoga dapat membantu mengurangi ketidaknyamanan fisik selama kehamilan, seperti morning sickness, sakit punggung, sakit pinggang, weak bladder, heartburn, kecemasan, sembelit dan lain-lain. ${ }^{8,15}$

Perasaan cemas dapat mengakibatkan ketegangan baik pada pikiran, fisik, otot panggul serta otot segmen bawah rahim. Ketegangan ini nantinya akan dapat menganggu pada saat proses persalinan berlangsung. Pada kehamilan trimester ke-III yaitu 28-40 minggu, bahwa kecemasan menjelang persalinan akan dapat muncul pertanyaan dan bayangan seperti, apakah ibu dapat melahirkan normal, bagaimana cara mengejan, apakah akan terjadi sesuatu saat melahirkan, atau apakah bayi lahir selamat, akan semakin sering muncul dalam benak ibu hamil. Pada ibu hamil Trimester III tingkat kecemasan semakin serius dan intensif seiring dengan mendekatnya proses kelahiran. ${ }^{5,17}$

Menurut penelitian Rizky Ayu dikatakan bahwa terjadi penurunan kecemasan pada primgravida. Penelitian menyebutkan bahwa sebelum diberikan treatment terdapat 14 orang ibu hamil primigravida $(87,5 \%)$ yang memiliki tingkat kecemasan sesaat yang tinggi, namun setelah diberikannya treatment maka terjadi penurunan menjadi 8 orang (50\%) ibu hamil primigravida yang mengalami kecemasan. ${ }^{15}$ Yoga dapat memberikan pengaruh positif pada kesehatan dan gaya hidup dengan mengubah gaya berfikir, perasaan, dan reaksi kita terhadap situasi kehidupan yang sedang kita jalani, dan yoga dapat membantu ibu hamil mengurangi rasa kecemasan yang dihadapi selama masa kehamilan. ${ }^{5,17}$

\section{Kesimpulan}

Sebagian besar ibu hamil primigravida mengalami rasa kecemasan baik tingkat ringan sampai berat. Terdapat perbedaan yang bermakna antara senam prenatal yoga dengan tingkat kecemasan pada ibu hamil primigravida trimester III.

\section{Daftar Pustaka}

1. Wahyuni, Layinatun Ni'mah. Manfaat Senam Hamil Untuk Meningkatkan Durasi Tidur Ibu Hamil. Kesehat Masy. Published online 2013:145-152. https:// journal. unnes. ac.id/nju /index. php /kesmas.2013.

2. Yulinda Y, Purwaningsih D dan Sudarta CM. Latihan Yoga Dapat Menurunkan Tingkat Kecemasan pada Siklus Mentruasi Remaja Puteri. J Ners dan Kebidanan Indones. 2017;5(1):20. doi:10.21927/jnki.5(1).20-26. 2017

3. Curtis K, Weinrib A, \& Katz J. Systematic review of yoga for pregnant women: Current status and future directions. Evidence-based Complement Altern Med. 2012;2012. doi:10.1155/2012/715942.2012

4. Maharani $\mathrm{T}$ dan Yesie A. Modul Pelatihan Prenatal Gentle Yoga. Jawa Tengah.; 2012.

5. Amalia A. Tetap Sehat Dengan Yoga "Berbagi Latihan Yoga Untuk Mengatasi Masalah Siklus Bulanan, Hamil, Pascamelahirakan.; 2015.

6. Cramer H, Frawley J, Steel A, Hall H, Adams J, Broom A, et al. Characteristics of women who practice yoga in different locations during pregnancy. BMJ Open. 2015;5(8):1-7. doi:10.1136/bmjopen-2015-008641

7. Rafika R. Efektifitas Prenatal Yoga terhadap Pengurangan Keluhan Fisik pada Ibu Hamil Trimester III. J Kesehatan. 2018;9(1):86. doi:10.26630/jk.v9i1.763

8. Aswitami NGAP. Pengaruh Yoga Antenatal Terhadap Tingkat Kecemasan Pada Ibu Hamil TW III Dalam Menghadapi Proses Persalinan Di Klinik Yayasan Bumi Sehat. J Kesehat Terpadu. 2017;1(1):1-5. doi:10.36002/jkt.v1i1.155. ISSN : 2549 - 8479

9. Profil Dinas Kesehatan Kabupaten Mukomuko. Profil Dinas Kesehatan Kabupaten Mukomuko. ; 2018.

10. Profil Dinas Kesehatan Kabupaten Mukomuko. Profil Dinas Kesehatan Kabupaten 
Mukomuko.; 2019.

11. Perawatan P. Data Ibu Hamil Di Puskesmas Perawatan Lubuk Pinang; 2018.

12. Perawatan P. Data Ibu Hamil Di Puskesmas Perawatan Lubuk Pinang; 2019.

13. Harahap SD, Utami S, dan Huda N. Efektivitas Yoga Terhadap Kualitas Tidur Ibu Hamil. J Online Mhs Bid Ilmu Keperawatan. 2018;5:1-9.

14. Mitra. Manajemen Dan Analisis Data Kesehatan. CV Andi Offset; 2015.

15. Apriliani R dan, Wahyudi H. Pengaruh Yoga prenatal terhadap kecemasan sesaat dalam menghadapi persalinan pada primigravida. Pros Psikol. Published online 2010:287-293.ISSN:2460-6448

16. Ashari A, Pongsibidang GS dan Mikhrunnisai A. Pengaruh Senam Prenatal Yoga terhadap
Penurunan Kecemasan Ibu Hamil Trimester III Influence of Yoga Prenatal Gym to Decreasing in Anxiety of Third Trimester Pregnant Women. 2019;15(1):55-62. DOI http://dx.doi.org/10.30597/mkmi.v15i1.5554

17. Christian VL. Teaching Prenatal Sun and Moon Yoga Studio. Teach Prenat. 2014;(April):0-25.

18. Parmiana B. Hubungan Antara Senam Yoga Dengan Tingkat Kecemasan Dalam Menghadapi Persalinan pada Primigravida. / Jurnal Ilmu Keperawatan dan Kebidanan Vol.10 No.2 (2019) 291-296

19. Macdonald-heilandt BK. Basic Prenatal Yoga Sequence. Published online 2015. http://www.mamanurture.ca/wp-content/uploads/ 2015/01/Basic-Prenatal-Yoga-Sequence.pdf 